\title{
QUALITY OF CHILD HEALTH CARE IN THE FAMILY HEALTH STRATEGY
}

\author{
Maria Lucélia da Hora Sales ${ }^{1}$, Liz Ponnet ${ }^{2}$, Carlos Eduardo Aguilera Campos ${ }^{3}$, \\ Marcelo Marcos Piva Demarzo², Cláudio Torres de Miranda ${ }^{4}$
}

\begin{abstract}
Objective: to verify the quality of child health care in the Family Health Strategy (FHS) in a state capital of Northeastern Brazil. Methods: a descriptive study using a quantitative approach was carried out in 2010 with 66 primary care (PC) teams represented by their doctors and nurses. The survey used part of the Evaluation for Quality Improvement of the Family Health Strategy ${ }^{2}$ (AMQ), a self-rating instrument of the Brazilian Ministry of Health which evaluates the FHS actions and services and classifies them by the following quality-based standards of care: Elementary, undergoing development, Consolidated, Good or Advanced. Results: $84.1 \%$ of the FHS-teams rated themselves as providing "Elementary" actions and services, and $47.7 \%$ of them considered that they provided "Advanced" ones. The health teams with less than four years of implementation rated themselves better. Conclusion: these findings suggest that most of the FHC-teams are providing care with an elementary standard of quality, and indicate that better quality child care is apparently delivered with by teams with less time of implementation.
\end{abstract}

Key words: health care quality. access. evaluation of health systems. family health. child health. (public health).

\section{INTRODUCTION}

Child health care in Brazil has undergone transformations over recent decades as regards advances in technical and scientific knowledge, public policies, and the involvement of various stakeholders and segments of society ${ }^{1,2}$. For example, public health policies have focused on infant mortality, which reflects not only the health status, but also the quality of life of populations ${ }^{3}$.

Changes in the care model has been induced within the Unified Brazilian Health System (SUS) by the Ministry of Health mainly by means of the creation of the Family Health Strategy (FHS) in 1994, initially called Family Health Program (PSF), sought to reorient from a model that favored the biomedical approach and spontaneous demand, favored decades to one with a focus on the health needs of individuals, families and communities, according to the attributes of Primary Health Care ${ }^{4,5}$ This proposal, despite the inherent by complex challenges and difficulties, has been assumed by all federal entities, based on the SUS core principles of universal access, equity, comprehensiveness care, community-based context, and integration of the health care network ${ }^{6-8}$.

Brazil is ranked second in the list of countries able to achieve the goal of reducing child mortality by two-thirds (the Millennium Development Goal 4 of the World Health Organization ${ }^{9}$ ), according to UNICEF, in its publication "State of the World's Children 2008 - Child Survival"2. The Brazilian Family Health Strategy model has been recognized as one of the most effective health policies to reduce

1 Department of Public Health, State University of Health Sciences of Alagoas - UNCISAL.

2 Department of Preventive Medicine, São Paulo School of Medicine, Federal University of São Paulo - UNIFESP

3 Department of Program for Primary Health Care, School of Medicine, Federal University of Rio de Janeiro Medical School - UFRJ

4 Department of Community Medicine, Federal University of Alagoas Medical School - UFAL Corresponding author: luceliahora@bol.com.br

Suggested citation: Sales MLH, et al. Quality of child health care in the Family Health Strategy; Journal of Human Growth and Development 2013; 23(2): 151-156

Manuscript submitted June 01 2012, accepted for publication Dec 192012. 
child mortality, and that could be implemented by other countries to improve the current models of child care worldwide ${ }^{9-10}$.

Despite this fact, the process of implementing the Family Health Strategy in Brazil is not homogenous in terms of coverage and quality concerning the country regions. In Maceió, Capital of the State of Alagoas, Northeastern Brazil, it was begun in 1996 by the health district number 5, and in 2001 the number of FHS-teams was 57, with $24 \%$ of the municipal population covered. Between 2004 and 2006 , there was a slight increase, reaching up to $27 \%$ of coverage, and the expansion included all the seven health districts of Maceió, but not uniformly. For example, the $5^{\text {th }}$ health district, despite being one of the most populous and with high social vulnerability, had the lowest coverage of the FHS-teams ${ }^{11}$. Nowadays, about fifteen years later, the process of implementation is still incomplete', and the studies evaluating its quality are scarce as well, despite the States being one of the pioneers in implementing the FHS.

In 2005, the Ministry of Health launched an instrument for evaluation of the FHS, called the 2Evaluation for Quality Improvement of the Family Health Strategy ${ }^{2}$ (Avaliação para Melhoria da Qualidade da Estratégia Saúde da Família - AMQ) ${ }^{12}$. Focused on self-evaluation by the main stakeholders (managers and health professionals), and presenting reference standards for the organization of actions and services, the instrument aims to improve the quality of actions and services provided in the Family Health Strategy ${ }^{13}$. The instrument, as proposed by the Ministry of Health, consists of two dimensional analysis factors: one focused on management issues and the other on the health care itself. The first approaches the subdimensions related to development of the Family Health Strategy such as technical coordination and structure of health units, being directed to health managers and coordinators of the primary care health units ${ }^{13}$. The other dimension is the object of this study, and discusses the aspects of the consolidation of this model of health care. The AMQ works with the hypothesis that the awareness of these aspects, through the perception of health professionals and managers, will help to consolidate the Family Health Strategy by improving the quality of actions and services. The instrument includes the actions undertaken in child health care, focusing also on quality of care ${ }^{13}$.

In this context, the main goal of this study is to evaluate the quality of child health care provided by the FHS-teams in a capital of Northeastern Brazil using the AMQ.

\section{METHODS}

This is a descriptive and cross-sectional study carried out in 2010 , through a survey among doctors and nurses of the Family Health Strategy teams of
Maceió, State of Alagoas, Brazil, using a quantitative approach. All the primary care health units of Maceió implemented at the time of the study were included (72 FHS teams from 35 health units). The municipality of Maceió is divided into seven health districts, covering the 51 neighborhoods in urban and rural areas, with a total population of 924,143 inhabitants in 2008, according to the Brazilian Institute of Statistics (IBGE). The city of Maceió is the most populous of the State and has autonomy in organizing its own health system at all levels of complexity, being the reference city for other municipalities. FHS has been implemented over 15 years and all the health care professionals employed are public health officers with a public career (statutory).

The interviews with health professionals were conducted in their own health units during working hours. Doctors and nurses answered the same questions together at the same time, reducing the personal judgement of on the answers, and the tendency to answer more positive as by expected on self-assessment tools.

The survey used part of the instrument "Evaluation for Quality Improvement of the Family Health Strategy" (AMQ), specifically the subdimension "Child Health" and its dimension "Health Care"12. We chose to focus on the subdimension "Child Health" as the topic is relevant as discussed above, and because of the possibility of deepening the data analysis.

Each health activity or service has been categorized in one of the five standards of the quality of care of the AMQ questionnaire, such as Elementary; Undergoing Development; Consolidated, Good, and Advanced ${ }^{12}$. This classification requires the achievement of different levels of complexity, not allowing the establishment of points of specific cuts, nor the ranking between teams ${ }^{13}$.

The quality standard "Elementary (E)" considers the following actions in the subdimension Child health: updated record of children up to five years; evaluation and completion of child care in all situations of search for care; preparation of the teams to recognize and guide the actions related to dehydration, the development of systematic actions to encourage breastfeeding in prenatal and postpartum care, $80 \%$ or more of children under one year old with follow up of growth and development, and $90 \%$ or more of the children under one year old of the area covered with an updated vaccine calendar ${ }^{12}$.

The quality standard of care "in Development (D)" consists of the following health actions: priority of care for children with an alert sign brought to the family health unit; monitoring by teams of $80 \%$ or more of children under 5 years in risk situations, and two visits to the newborn (NB) in their first month of life ${ }^{12}$.

The quality standard of care "Consolidated (C)" consists of follow up of $80 \%$ or more of the children between one and five years old; follow-up 
of children with asthma according to an established clinical protocol, and the prevalence of $90 \%$ or more of exclusive breastfeeding at 30 days of birth ${ }^{12}$.

The quality standard "Good (B)" evaluates reduction of the absolute number of admissions for acute respiratory infection (ARI) in children up to 5 years, or the absence of cases, incidence in descending curve or absence of malnutrition in children under 2 years; reduction in the absolute number or absence of cases of newborns with low birth weight, investigation of all infant deaths, and prevalence of $60 \%$ or more of exclusive breastfeeding at 6 months ${ }^{12}$.

The quality standard "Advanced (A)" evaluates the follow up of $80 \%$ or more of children between 5 and 10 years old; investigation of all infant and fetal deaths in the last 12 months, prevalence of breastfeeding at 12 months, $80 \%$ or more of the NB with a consultation in their first week of life ${ }^{12}$.

The answers to the self-assessment questionnaires were ${ }^{2}$ yes or no, according to the original model of the instrument, whose principles and quality criteria were defined and validated by established parameters. The "quality standards" were characterized from the activities performed by the team, the number of positive responses ("yes") being considered in relation to all the questions above ${ }^{12}$.

In the description of the results, the teams were divided according to their Health District (I to VII). In analyzing the results, we compared the quality standards in relation to the length of the implementation time of the teams as to the time of this study (up to 04 years, 5 years or more). These data were obtained from the professionals interviewed.

We used descriptive statistics (absolute distributions and percentage) and inferential statistical techniques (chi-squared test, or Fisher exact test when it was not possible to use the chisquare test). The margin of error in the decision of the statistical tests was $5.0 \%$. The software used for data entry and retrieval of statistical calculations was the Statistical Package for Social Sciences (SPSS (C) version 15.0 for Windows, SPSS Inc. Given the standards of research involving humans, the study was approved by the Ethics Committee of the Federal University of São Paulo (Protocol No. 0418/09).

\section{RESULTS}

Of the 72 FHS-teams, 6 refused to participate in this study. The data collection was performed in the remaining 66 FHS-teams that were characterized by their health district and implementation running time (in years), as described in table 1 . Concerning number of people covered, most of the teams attended between 2400 and 4500 persons (72.7\%). Tables 2 and 3 show AMQ results for the standards of the quality of child care provided by the FHS-teams.

Table 1: Distribution of teams of the Family Health Strategy by health district and their running time of implementation (in years), Maceió-Brazil, 2010

$\begin{array}{lcc}\text { Variable } & \text { Number of Teams } & \% \\ \text { District } & 10 & 15,2 \\ \text { I } & 6 & 9,1 \\ \text { II } & 11 & 16,7 \\ \text { III } & 9,6 \\ \text { IV } & 5,6 \\ \text { V } & 5 & 15,2 \\ \text { VI } & 10 & 22,6 \\ \text { VII } & 15 & 15,2 \\ \text { Implementation Runing Time } & & 84,8 \\ \text { < 4 years } & 10 & \mathbf{1 0 0 , 0}\end{array}$

Table 2: Standards of quality of the child care by health district, average \%, Maceió-Brazil, 2010

$\begin{array}{lcccccccc}\begin{array}{l}\text { Standard } \\ \text { Elementary(E) }\end{array} & \text { I } & \text { II } & \text { III } & \begin{array}{c}\text { District } \\ \text { IV }\end{array} & \text { V } & \text { VI } & \text { VII } & \text { Total } \\ \begin{array}{c}\% \text { (average) } \\ \text { Developing(D) } \\ \% \text { (average) }\end{array} & 81.7 & 94.4 & 86.4 & 83.3 & 93.3 & 83.3 & 77.8 & \mathbf{8 4 . 1} \\ \begin{array}{c}\text { Consolidated(C) } \\ \% \text { (average) }\end{array} & 80.0 & 55.6 & 69.7 & 63.0 & 80.0 & 60.0 & 75.6 & \mathbf{6 9 . 7} \\ \begin{array}{c}\text { Good(G) } \\ \% \text { (average) }\end{array} & 78.0 & 72.2 & 54.5 & 33.3 & 80.0 & 46.7 & 66.7 & \mathbf{5 8 . 6} \\ \begin{array}{c}\text { Advanced(A) } \\ \% \text { (average) }\end{array} & 47.5 & 29.2 & 54.5 & 52.8 & 35.0 & 47.5 & 51.7 & \mathbf{4 7 . 7}\end{array}$


Table 3: Standards questions that showed statistical significance in relation to the implementation running time (in years) of the Family Health Strategy teams, Maceió-Brazil, 2010

\begin{tabular}{|c|c|c|c|c|c|c|c|}
\hline \multirow{3}{*}{ Issues } & \multicolumn{4}{|c|}{ Running Time ( in years) } & \multirow{2}{*}{\multicolumn{2}{|c|}{ total }} & \multirow{3}{*}{ p Value } \\
\hline & \multicolumn{2}{|c|}{5 years or more } & \multicolumn{2}{|c|}{ Up to 4 years } & & & \\
\hline & $\mathrm{N}$ & $\%$ & $\mathrm{n}$ & $\%$ & $\mathrm{n}$ & $\%$ & \\
\hline \multicolumn{8}{|c|}{ Q5.17Ba } \\
\hline Yes & 32 & 59.3 & 10 & 100.0 & 42 & 65.6 & $\mathrm{p}^{(1)}=0.012$ \\
\hline No & 22 & 40.7 & - & - & 22 & 34.4 & \\
\hline TOTAL & 54 & 100.0 & 10 & 100.0 & $64 *$ & 100.0 & \\
\hline \multicolumn{8}{|c|}{ Q5.21A $\mathrm{A}^{\mathrm{b}}$} \\
\hline Yes & 31 & 60.8 & 10 & 100.0 & 41 & 67.2 & $\mathrm{p}^{(1)}=0.023$ \\
\hline No & 20 & 39.2 & - & - & 20 & 32.8 & \\
\hline TOTAL & 51 & 100.0 & 10 & 100.0 & $61 *$ & 100.0 & \\
\hline
\end{tabular}

(1) The test of Fisher.

a Q5.17B: All neonatal deaths are investigated (Standard level = "Good").

b Q5.21A: All fetal and infant deaths occurred in the last 12 months were investigated (Standard level = "Advanced").

* The teams who refused to answer these questions were excluded.

\section{DISCUSSION}

All the doctors and nurses of the sixty-six teams of the Family Health Strategy studied. were interviewed $(\mathrm{n}=122)$. Table 1 shows the characterization of the teams by health district (HD) and time of implementation (in years). It was found that the number of teams varied between HD, and the majority of teams had been operational for more than five years $(84.8 \%)$. In relation to the $A M Q$ quality of care standards, $84.1 \%$ of the FHS-teams rated themselves as providing elementary care, $82,1 \%$ as providing good care, and $47.7 \%$ as providing advanced care.

When taking the operational time of the FHSteams into account, the "Elementary" (E) quality of care standard had the highest prevalence of positive answers. It was observed that the largest percentage difference occurred in the question related to the "updated record of children up to five years old", in which the highest percentage of positive answers was recorded between the teams working up to four years $(90.0 \%)$, while the established teams with five years or more of working was $64.3 \%$, although this difference was not statistically significant ( $p=0.08)$. Regarding the standard under Development ${ }^{2}(D)$, it was found that the biggest difference between the two ranges of working experience time was in the item " $80 \%$ or more of the newborns received two consultations in the $1^{\text {st }}$ month of life", the highest value being among those who had more than five years in operation ( $64.8 \%$ vs. $50.0 \%)$, also not statistically significant $(p>0.05)$.

In the Consolidated ${ }^{2}$ (C) standard it was observed that the largest difference occurred in the item " $80 \%$ or more of children between one and five years old in the area are being assisted by the Family Health Strategy (FHS)", having, on average, higher prevalence of "yes" answers among teams which had up to four years in operation ( $90.0 \%$ vs. $67.9 \%)$, also not statistically significant ( $p>0.05)$. In the results regarding the standard $B\left(\operatorname{Good}^{2}\right)$ it was ascertained that the question "All neonatal deaths are investigated" was the only one that was significantly associated with running time of the FHS $(p=0.012)$. To that question, the percentage of positive answers was $100.0 \%$ among the teams until four years of operation, and $59.3 \%$, on average, among those with five years or more (Table 3 ). Regarding the Advanced ${ }^{2}$ (A) standard, it was observed that the question "All fetal and infant deaths that occurred in the last 12 months were investigated" was the only one that was significantly associated with the running time of the team $(p=0.023)$. The percentage of positive answers was $100.0 \%$ among the inquiry team of up to four years of operation, and $60.8 \%$ on average among those with five years or more (Table 3 ).

The way the AMQ was conceived, the teams that have quality of care standards such as E, D and $\mathrm{C}$ are classified "still in the inimplementation process of the FHS", while teams that present standards B and A as "evolution to the quality of actions ", following an incremental logical analysis ${ }^{12}$. This means that the yes ${ }^{2}$ answers should be a larger number in the lower incremental levels. In the current study, this logic has not been verified, because $E$ and $B$ had the best levels of yes ${ }^{2}$ responses. For example, it would be expected that a certain percentage of positive answers to the "Good" standard would only be achieved after the incremental standards levels E, D, and C had been better evaluated. This pattern of responses that does not match the standards criteria established by $A M Q$ has already been observed by Sarti ${ }^{14}$.

These results may indicate the need to review the incremental logic assigned to each standard in 
the $A M Q$, or even the actions assigned to them, and it is a first limitation in the analysis of our results. Another limitation is the AMQ self-evaluative characteristic which is a well-known bias, and therefore our results should be seen with caution, not permitting generalizations. On the other hand, the AMQ constituted one of the main evaluative instruments among policies for improving the quality of FHS in Brazil, and there are few studies that use the AMQ as strategy to evaluate the quality of the child care in the $\mathrm{FHS}^{14}$, and so our results may constitute a relevant reference for similar studies in the future.

It was observed that the E standard had the highest percentage of positive answers among all the HD of Maceió ( $84.1 \%$ ). This standard presents key elements of structure and most basic actions expected for the $\mathrm{FHS}^{12}$. At the same time, the standard B showed the second highest level of positive response $(82.1 \%)$. This standard level stresses the reduction in the hospital admissions for Acute Renal Failure, reduction of malnutrition in children under 2 years old, and the reduction of low birth weight in the newborns. These issues indicate health actions of greater complexity and longitudinal lasting results and support ${ }^{12}$. Thus the FHS in Maceió presents standards "in implementation process" with "evolution to the quality of actions" according to the AMQ. Due to the lack of studies on the subject, it has been hypothesized that these results may reflect the limitation of the instrument itself, as discussed above, or even present an expected profile of the FHS in centers with longer implantation of the strategy, as Maceió. Some studies have shown the impact of FHS on malnutrition and infant mortality indicators, indicating that a longer implementation is related to significant reductions in these indicators, especially in regions with worse socioeconomic indicators ${ }^{10,15}$. In 2003, a study in the city of Sobral (Ceara, Brazil) showed that after

\section{REFERENCES}

1. Figueiredo NMADE, Tonini T. SUS e PSF para enfermagem: práticas para o cuidado em saúde coletiva. Yendis Editora. São Caetano do Sul, SP: 2007; p.18 e 24.

2. Mello DF, Lima RAG. Êxito técnico, sucesso prático e sabedoria prática: bases conceituais hermenêuticas para o cuidado de enfermagem à criança [texto da internet]. Ribeirão Preto. [citado em 06 fev 2010]. Revista latinoamericana de enfermagem: 2009; 17(4). Disponível em: <http://www.scielo.br/scielo. php? pid=s010411692009000400022\&script =sci_arttext\&tlng=pt.

3. United Nations Children's Fund [Internet]. Brasília: UNICEF (BR) [cited 2008 jun 08]. Situação da Infância Brasileira 2006. Crianças the implementation of the FHS there was no record of death by Acute Renal Failure, showing a significant improvement in the infant mortality rate $^{16,17}$. It is likely that the provision of preventive and educational actions by the FHS-teams and the integration of clinical and public health actions ${ }^{18}$ are contributing to these results and to the improvement of the quality of actions, especially in the child health services.

It is interesting to note that in this study the teams of up to 4 years of implementation tended to give more positive answers on many child health actions, compared to those with 5 years or more of implementation, mainly in standards $B$ and $A$. It would be expected that the continued implementation process of the FHS would lead to cumulative technical skills that, in theory, would increase the competency and quality of care ${ }^{14}$. The scientific literature is also limited about this question, but it is possible to suggest some hypotheses to explain this finding: tendency for most critical and realistic answers on the part of more experienced professionals, or, on the other hand, most appropriate technical training of new professionals, due to several recent initiatives for the improvement of the health professionals' training quality with a special focus on primary health care, started-up only in the last decade in Brazil19.

In conclusion, the quality level of the child care actions and services in the FHS of Maceió currently alternates elementary ("in implementation") with advanced standards ("evolution to the quality of actions"), and teams with less time of implementation tended to rate themselves with more positive statements in the area of child care. Moreover, critical reflection should be part of the evaluative context of health services, and the results and reflections raised by our study may provide support and insights for future policies addressing the improvement of the quality of care in the Brazilian FHS.

de até 6 anos: o direito à sobrevivência e ao desenvolvimento. Available from: http:// www.unicef.org/brazil/pt/resources_ 10167.htm.

4. Teixeira C, Fontes S, Pereira J. Modelo de atenção à saúde: promoção, vigilância e saúde da família. Edufba. Salvador: 2006.

5. Brasil. Ministério da Saúde. Conselho nacional de saúde. SUS 20 anos - a saúde do tamanho do brasil. [texto da internet] Brasília (DF); 2008. [Citado em 24 abr. 2010]. Disponível em: http://conselho.saude.gov.br/ultimas_noticias/ 2008/Carta20anosdoSUS.pdf.

6. Slomp FM, Falleiros de Mello D, Scochi CGS, Leite AM. Assistência ao recém-nascido em um Programa de Saúde da Família. Rev. Esc. Enferm. USP. São Paulo: 2007; 41(3): 441-446. 
7. Brasil. Ministério da Saúde. Secretaria de Atenção à Saúde Departamento de Ações Programáticas Estratégicas. Agenda de compromissos para a saúde integral da criança e redução da mortalidade infantil. Brasília (DF); 2005a.

8. Gil CRR. Formação de recursos humanos em saúde da família: paradoxo e perspectivas. Cad. Saúde Pública. 2005; 21(2):490-498.

9. Brasil. Ministério da Saúde. Saúde da criança: nutrição infantil, aleitamento materno em alimentação complementar. Telessaúde. Brasília: 2009.

10. Aquino $R$, Oliveira NF, Barreto ML. Impact of the Family Health Program on Infant Mortality in Brazilian Municipalities. American Journal of Public Health, New York 2009, 99(1): 87-93.

11. Maceió. Plano municipal de saúde: triênio 20102013, participar para viver com saúde. Coordenadoria geral de planejamento controle e avaliação. Secretaria municipal de saúde. Maceió: 2009.

12. Ministério da Saúde. Avaliação para melhoria da qualidade qualificação da Estratégia Saúde da Família. Brasília: Ministério da Saúde; 2005.

13. Silva JM, Caldeira AP. Modelo assistencial e indicadores de qualidade da assistência: percepção dos profissionais da atenção primária à saúde. Cad. Saúde Pública. 2010; 26(6):1187-1193.

14. Sarti TD. Avaliação da Estratégia Saúde da Família no Espírito Santo utilizando o instrumento de avaliação para melhoria da qualidade da Estratégia Saúde da Família (AMQ). Dissertação de Mestrado UFES. 2009.

15. Monteiro CA. Causas do declínio da desnutrição infantil no Brasil, 1996-2007. Revista de Saúde Pública, São Paulo 2009, 43(1):35-43.

16. Machado MMT. Avaliação das atividades dos enfermeiros da saúde da família, na atenção à saúde da criança de zero a dois anos em três municípios do Ceará [tese]. Ceará: Programa de Pós-Graduação em Enfermagem da Universidade Federal do Ceará; 2005.

17. Silva AC. Saúde da família saúde da criança: a resposta de Sobral \Anamaria Cavalcante e Silva. Aderaldo \& Rothschild São Paulo: 2007.

18. Atrash HK, Carpentier R. The evolving role of public health in the delivery of health care. J. Hum. Growth Dev. 2012; 22(3): 396-399.

19. Frenk J, Chen L, Bhutta ZA, et al. Health professionals for a new century: transforming education to strengthen health systems in an interdependent world. Lancet 2010; 376: $1923-58$. 